\title{
Inhibition of prostate cancer DU145 cell growth with small interfering RNA targeting the SATB1 gene
}

\author{
QIANG WANG $^{1,2^{*}}$, CHUN-SHENG YANG $^{3 *}$, ZU-XIN MA $^{1 *}$, JIA-CUN CHEN $^{1}$, \\ JUN-NIAN ZHENG ${ }^{4}$, XIAO-QING SUN ${ }^{1}$ and JUN-QI WANG ${ }^{1}$ \\ ${ }^{1}$ Department of Urology, The Affiliated Hospital of Xuzhou Medical University, Xuzhou, Jiangsu 221002; \\ ${ }^{2}$ Department of Urology, The First Clinical Medical College, Nanjing University of Chinese Medicine, Nanjing, \\ Jiangsu 210046; ${ }^{3}$ Department of Dermatology, Affiliated Huai'an Hospital of Xuzhou Medical University, \\ The Second People's Hospital of Huai'an, Huai'an, Jiangsu 223002; ${ }^{4}$ Center of Clinical Oncology, \\ Affiliated Hospital of Xuzhou Medical University, Xuzhou, Jiangsu 221002, P.R. China
}

Received April 22, 2017; Accepted December 8, 2017

DOI: $10.3892 /$ etm.2018.5792

\begin{abstract}
Prostate cancer is a common visceral cancer of men worldwide. It is important to develop a more effective treatment for prostate cancer to overcome the treatment resistance that occurs with recurrence. RNA interference has been demonstrated to be a powerful tool for gene knockdown and has potential as a cancer treatment. It has been previously demonstrated that staining of special AT-rich sequence-binding protein 1 (SATB1) was stronger in prostatic carcinoma with metastasis compared with prostatic carcinoma without metastasis. In the present study, SATB1 small interfering (si)RNA was transfected into prostate cancer DU145 cells and normal human lung fibroblast cells, and cell proliferation was investigated using a Cell Counting kit-8. Three siRNA were transfected into cells using siPORT Lipid Transfection agent, and blank control and negative control groups were established. The cells were harvested and SATB1 mRNA and protein expression was determined by reverse transcription-quantitative polymerase chain reaction and western blotting, respectively. DU145 cell adhesion, migration and invasion capabilities were determined using cell adhesion, Transwell and Transwell with Matrigel assays, respectively. Silencing SATB1 significantly inhibited DU145 cell growth, adhesion, migration and invasive capability in vitro, indicating that a SATB1-targeting siRNA was successfully engineered.
\end{abstract}

Correspondence to: Dr Jun-Qi Wang, Department of Urology, The Affiliated Hospital of Xuzhou Medical University, 99 West Huai-Hai Road, Xuzhou, Jiangsu 221002, P.R. China

E-mail: a5716589@163.com

*Contributed equally

Key words: prostate cancer, special AT-rich sequence-binding protein 1, small interfering RNA, metastasis, matrix metalloproteinase 2
The results of the present study suggest that SATB1 siRNA may be a potential agent for treating human prostate cancer.

\section{Introduction}

Prostate cancer is a common visceral cancer of men worldwide (1). Patients in which the disease is clinically localized at diagnosis typically receive a radical prostatectomy or radiotherapy treatment $(2,3)$. However, there is a $20-40 \%$ recurrence rate within a year following these treatments (4). Patients with recurrent, metastatic or locally advanced prostate cancer are primarily treated with androgen deprivation therapy (ADT) (5). However, all patients eventually develop resistance to ADT, termed castration-resistant prostate cancer (CRPC). Therefore, it is necessary to develop a more effective treatment for CRPC.

Special AT-rich sequence-binding protein 1 (SATB1) is a transcription factor that regulates histone modifications and serves an important role in gene transcription (6). It has been previously demonstrated that SATB1 is overexpressed in a variety of types of malignant cancer, including nasopharyngeal carcinoma (7), cutaneous malignant melanoma (8), osteosarcoma (9) and small cell lung cancer (10). The authors of the present study have previously demonstrated that SATB1 expression was positively correlated with bone metastasis and the Gleason score of prostatic carcinomas (11). SATB1 overexpression promoted prostate cancer cell proliferation and invasion, whereas SATB1 knockdown inhibited it (11). These findings indicated that SAYB1 serves an oncogenic role in prostate cancer development (6-11).

RNA interference may downregulate target genes and has been suggested as a potential therapeutic strategy in human cancer therapy (7). RNA interference involves post-transcriptional gene silencing via a process in which double-stranded RNA inhibits gene expression in a sequence-dependent manner through degradation of the corresponding mRNA (12). Gene knockdown and its inhibitory action on gene expression have been successfully observed in rat (13) and human cells cultured in vitro (14). The inhibition of several targets using synthetic small interfering (si)RNA 
suppresses the growth of various cancer cell lines and provides a potential nucleotide-based approach for suppressing gene products for loss of function analyses $(7,8)$.

Based on previous studies, three siRNA against SATB1 were designed and the efficacy of SATB1 siRNA transfection was investigated with regard to prostate cancer cells and the suppression of SATB1 expression in vitro. The findings of the present study suggest that SATB1 may be an important target protein in prostate cancer cells.

\section{Materials and methods}

Cell culture. The prostate cancer cell line DU145 and normal human lung fibroblast (NHLF) cells were purchased from the Shanghai Cell Collection (Shanghai, China) (15). The cells were cultured in Dulbecco's modified Eagle's medium (DMEM; Gibco; Thermo Fisher Scientific, Inc., Waltham, MA, USA) supplemented with $10 \%$ heat-inactivated fetal bovine serum (FBS; Gibco; Thermo Fisher Scientific, Inc.), 4 mM glutamine, $50 \mathrm{U} / \mathrm{ml}$ penicillin and $50 \mu \mathrm{g} / \mathrm{ml}$ streptomycin at $37^{\circ} \mathrm{C}$ in a humidified atmosphere with $5 \% \mathrm{CO}_{2}$. The cells were screened routinely to verify the absence of mycoplasma contamination in the log phase of growth.

siRNA preparation. siRNA duplex sequences were synthesized, purified and annealed by Ambion (Thermo Fisher Scientific, Inc.). The three SATB1 siRNA targeting the region containing nucleotides 2147-2185 of the SATB1 complementary DNA (ncbi.nlm.nih.gov; accession no. AB6304) were as follows: SATB1 siRNA1 (siRNA1), sense 5'-CGAGUCCUUAAA CCAAACAATT-3' and antisense 3'-UUGUUGGUUUAA GGACUGCTT-5'; SATB1 siRNA2 (siRNA2), sense 5'-GAG GUGUCUUCCGAAAUCUTT-3' and antisense 3'-AGAUUU CGGAAGACACCUCTT-5'; SATB1 siRNA3 (siRNA3), sense 5'-CCCAGUCUUUGCUGGUAAATT-3' and antisense 3'-UUUACCAGCAAAGACUGGGTT-5'; and NC sense 5'-UUCUCCGAACGUGUCAGUTT-3' and antisense 3'-TTA AGAGGCUUGCACAGUGCA-5'. The selected sequences were submitted to the Basic Local Alignment Search Tool (ncbi.nlm.nih.gov/blast/) to ensure that the selected genes were targeted specifically. A green fluorescein-labeled (FAM) siRNA was purchased from Ambion (Thermo Fisher Scientific, Inc.) and used as the negative control (NC).

siRNA transfection. siRNA transfection was performed using siPORT ${ }^{\mathrm{TM}}$ Lipid Transfection agent (Ambion; Thermo Fisher Scientific, Inc.). A total of $3 \mu 1$ lipid and $3 \mu 1$ siRNA were diluted separately in $250 \mu 1$ Opti-MEM ${ }^{\circledR}$ I (Invitrogen; Thermo Fisher Scientific, Inc.). The diluted lipid was mixed with the diluted siRNA and the mixture was incubated for $20 \mathrm{~min}$ at room temperature for complex formation. The Opti-MEM $^{\circledR}$ I complex was added to each well of a 6 -well plate to a total volume of $200 \mu \mathrm{l}$ and the entire mixture was added to the cells in one well resulting in a final concentration of 10,50 or $100 \mathrm{nM}$ siRNA. The blank group was not transfected with anything. The cells were harvested and assayed at 24,48 or $72 \mathrm{~h}$ following transfection.

Detecting transfection efficiency under fluorescence microscopy. DU145 cells were plated at a density of
$10^{5}$ cells $/ 6 \mathrm{~cm}$ dish. The NC (FAM siRNA) and Blank group were used to transfect the cells for $24 \mathrm{~h}$. The cell transfection efficiency was detected under an Olympus fluorescence microscope (Olympus Corporation, Tokyo, Japan) and images were captured in the bright field at $24 \mathrm{~h}$ following treatment (magnification, x200).

Cell viability assay. The viability of the DU145 and NHLF cells was examined using a Cell Counting kit-8 (CCK-8; Shanghai Tongren Pharmaceutical Co., Ltd., Shanghai, China) according to the manufacturer's protocol. Briefly, $5 \times 10^{3}$ cells/well were seeded in 96-well plates and cultured for $48 \mathrm{~h}$ at $37^{\circ} \mathrm{C}$. A total of $10 \mu \mathrm{l}$ CCK- 8 solution was added to each well and the plates were incubated for $1 \mathrm{~h}$ at $37^{\circ} \mathrm{C}$. The absorbance at $450 \mathrm{~nm}$ was measured using a microplate reader. Results were representative of three individual experiments in triplicate.

$R N A$ extraction and reverse transcription-quantitative polymerase chain reaction ( $R T-q P C R)$. Total RNA was isolated from DU145 cells using TRIzol reagent (Invitrogen; Thermo Fisher Scientific, Inc.), according to the manufacturer's protocol. RNA was reverse transcribed at $37^{\circ} \mathrm{C}$ for $40 \mathrm{~min}$ using BeyoRT ${ }^{\mathrm{TM}}$ M-MuLV Reverse Transcriptase (Beyotime Institute of Biotechnology, Haimen, China). The thermal protocol for the PCR was $3 \mathrm{~min}$ at $94^{\circ} \mathrm{C}$, followed by 30 cycles of $30 \mathrm{sec}$ at $94^{\circ} \mathrm{C}, 30 \mathrm{sec}$ at $58^{\circ} \mathrm{C}$ and $1 \mathrm{~min}$ at $72^{\circ} \mathrm{C}$ and 1 cycle of $10 \mathrm{~min}$ at $72^{\circ} \mathrm{C}$. PCR amplifications were performed as described using SYBR ${ }^{\circledR}$ Green and TaqMan ${ }^{\mathrm{TM}}$ (Beyotime Institute of Biotechnology). The $2^{-\Delta \Delta \mathrm{Cq}}$ method of quantification was used as previously described (16). The following primers were used: $\beta$-actin, forward 5'-AGCGAGCATCCC CCAAAGTT-3' and reverse 5'-GGGCACGAAGGCTCATCA TT-3'; and SATB1, forward 5'-TGCAAAGGTTGCAGCAAC CAAAAGC-3' and reverse 5'-AACATGGATAATGTGGGG CGGCCT-3'. All primers were purchased from Invitrogen (Thermo Fisher Scientific, Inc.).

Western blot analysis. The DU145 cells were harvested from the plates and aliquots of cell extracts were separated on $12 \%$ SDS-PAGE. A radioimmunoprecipitation protein lysis extraction buffer (Beyotime Institute of Biotechnology) was used and the BCA method was used to determination the protein content. For each individual sample $20 \mu \mathrm{l}$ protein was loaded per lane into a $4 \%(\mathrm{w} / \mathrm{v})$ agarose gel and run in an electrophoresis buffer for $2 \mathrm{~h}$. The proteins were then transferred onto a nitrocellulose membrane and blocked by $3 \%$ bovine serum albumin (BSA; Gibco; Thermo Fisher Scientific, Inc.) at $37^{\circ} \mathrm{C}$ for $2 \mathrm{~h}$ and incubated overnight at $4^{\circ} \mathrm{C}$ with rabbit polyclonal antibodies (all dilution 1:1,000) directed against the following proteins: SATB1 (cat. no. PA5-30163; GenHunter Corporation, Nashville, TN, USA), matrix metalloproteinase 2 (MMP2; cat. no. AF902; Cell Signaling Technology, Inc., Danvers, MA, USA) and $\beta$-actin (cat. no. AB10024; Santa Cruz Biotechnology, Inc., Dallas, TX, USA). The membranes were then washed with a washing buffer (ph 7.5) consisting of $100 \mathrm{mM}$ Tris, $1.21 \mathrm{~g} ; 100 \mathrm{mM} \mathrm{NaCl}, 5.84 \mathrm{~g}$; and $0.1 \%$ Tween-20 $1 \mathrm{ml}$ and incubated with horseradish peroxidase-labeled goat anti-rabbit immunoglobulin G [(H+L); cat. no. ZB2301; dilution 1:2,000; OriGene Technologies, Inc., Beijing, China)] in Tris-buffered saline containing Tween-20 at $37^{\circ} \mathrm{C}$ for $2 \mathrm{~h}$ and developed using 
A

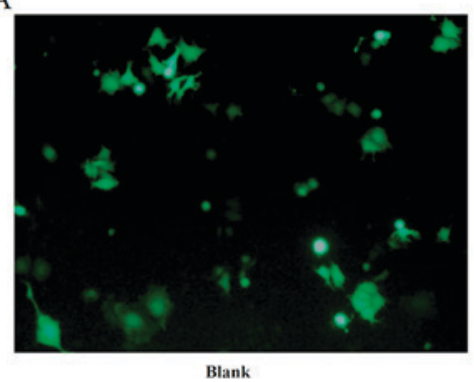

B

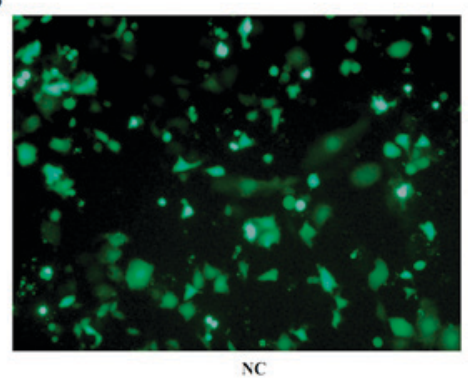

Figure 1. Transfection of siRNA into DU145 cells. Green fluorescein-labeled (A) NC group (FAM siRNA) and (B) the Blank group were transfected into DU145 cells. At $24 \mathrm{~h}$ following transfection, fluorescence microscopy revealed clearer cytoplasmic green fluorescence in the NC group than in the Blank group (magnification, x200). NC, negative control; siRNA, short interfering RNA; FAM, green fluorescein-label.

the nitroblue tetrazolium chloride/5-bromo-4-chloro-3-indolyl phosphate color substrate (Promega Corporation, Madison, WI, USA). The band densities were scanned and analyzed using ImageJ software version $1.48 \mathrm{u}$ (National Institutes of Health, Bethesda, MD, USA).

Cell adhesion, migration and invasion assays. Polyvinyl chloride microtiter plates (96 wells) were coated with $50 \mu \mathrm{l}$ SATB1 siRNA and incubated at $4^{\circ} \mathrm{C}$ overnight. Following washing with $0.9 \%$ sodium chloride, each well was filled with DMEM supplemented with $1 \%$ BSA and containing the cells, for $2 \mathrm{~h}$ at $37^{\circ} \mathrm{C}$ and washed again. For the adhesion assay the cells were detached using trypsin (Cell Signaling Technology, Inc.) digestion at $37^{\circ} \mathrm{C}$ for $24 \mathrm{~h}$, washed three times with $0.9 \%$ sodium chloride and resuspended in incomplete DMEM; the cells were subsequently added to the siRNA-coated plates at $2 \times 10^{4}$ cells/well in $100 \mu \mathrm{l}$ DMEM. Following $1 \mathrm{~h}$ incubation at $37^{\circ} \mathrm{C}$ in $5 \% \mathrm{CO}_{2}$, the unbound cells were removed by washing with incomplete DMEM. Adherent cells were fixed with a solution of $4 \%$ paraformaldehyde in $\mathrm{PBS}(\mathrm{pH} 7.2)$ at $37^{\circ} \mathrm{C}$ for $30 \mathrm{~min}$ and stained with $0.5 \%$ crystal violet at $37^{\circ} \mathrm{C}$ for $30 \mathrm{~min}$, and subsequently observed using a light microscope at magnification, x100. The absorbance of the plates was read on an ELX-800 spectrometer reader (BioTek Instruments, Inc., Winooski, VT, USA) at $490 \mathrm{~nm}$.

The cell migration and invasion assays were performed using a modified two-chamber migration apparatus with an $8-\mu \mathrm{m}$ pore size (Corning Incorporated, Corning, NY, USA). For the migration assays, the underside of a Transwell filter was coated with $10 \mu \mathrm{g} / \mathrm{ml}$ human plasma fibronectin (Sigma-Aldrich; Merck KGaA, Darmstadt, Germany) at $37^{\circ} \mathrm{C}$ overnight. Briefly, siRNA-transfected DU145 cells $\left(5 \times 10^{4}\right)$ and DMEM without FBS were seeded into the upper chambers and DMEM supplemented with $10 \%$ FBS was used to fill the lower compartment. Following $24 \mathrm{~h}$ incubation at $37^{\circ} \mathrm{C}$ in a humidified atmosphere containing $5 \% \mathrm{CO}_{2}$, the cells in the upper chamber were removed with a cotton swab. The filters were fixed in $95 \%$ methanol at $37^{\circ} \mathrm{C}$ for $30 \mathrm{~min}$ and stained with crystal violet at $37^{\circ} \mathrm{C}$ for $30 \mathrm{~min}$. The cells that migrated to the lower surface were counted in five light microscopic fields per filter at magnification, x100 in a minimum of three independent experiments.

For the invasion assay, a similar procedure was performed using Matrigel-coated (Sigma-Aldrich; Merck KGaA) Transwell chambers. Cells at the bottom of the wells were quantified following $48 \mathrm{~h}$ incubation at $37^{\circ} \mathrm{C}$ using a light microscope. Cells that migrated to the bottom surface of the membrane were observed under light microscopy and then photographed in five random fields at magnification, x100.

Statistical analysis. Data are expressed as the mean \pm standard deviation. Data were analyzed by one-way analysis of variance followed by Duncan's new multiple range method or the Newman-Keuls test. $\mathrm{P}<0.05$ was considered to indicate a statistically significant difference. All statistical analyses were performed by using SPSS version 13.0 for Windows (SPSS, Inc., Chicago, IL, USA) and each experiment was repeated five times.

\section{Results}

Detecting transfection efficiency under fluorescence microscopy. The NC (FAM siRNA) and the Blank group were used to transfect DU145 cells for $24 \mathrm{~h}$ as described above. The cell transfection efficiency was detected under fluorescence microscopy and images were captured in the bright field (Fig. 1). The green fluorescence within the cytoplasm was clearer in the $\mathrm{NC}$ group than in the blank group.

SATB1 and MMP2 expression following siRNA transfection. Three siRNA were transfected into cells using siPORT ${ }^{\mathrm{TM}}$ Lipid Transfection agent, and blank control (Blank) and NC groups were also established. Following $48 \mathrm{~h}$ transfection, the cells were collected and SATB1 mRNA and protein expression levels were detected using RT-qPCR and western blot analysis, respectively. The amplified fragment observed following RT-qPCR was of the expected size (Fig. 2A). The levels of SATB1 mRNA expression were significantly lower following siRNA2 transfection compared with the $\mathrm{NC}$ and Blank groups ( $\mathrm{P}<0.05$; Fig. $2 \mathrm{~B})$. siRNA2 had the most notable inhibitory effect compared with the other siRNA; SATB1 mRNA expression following siRNA2 transfection was $39.39 \pm 5.78 \%$.

Western blotting revealed that the levels of SATB1 protein expression following siRNA2 transfection were significantly lower than the levels in the $\mathrm{NC}$ and Blank groups ( $\mathrm{P}<0.05$; Fig. 3). SATB1 protein expression was $0.69 \pm 0.03 \%$ following siRNA1 transfection, $0.28 \pm 0.05 \%$ following siRNA2 transfection and $0.36 \pm 0.04 \%$ following siRNA3 transfection (Fig. 3A and B). Similar to the mRNA expression findings, siRNA2 had the most notable inhibitory effect of the siRNA groups. As siRNA2 had the most notable inhibitory effect of the siRNA groups, only siRNA2 transfection was investigated in the following experiments. 

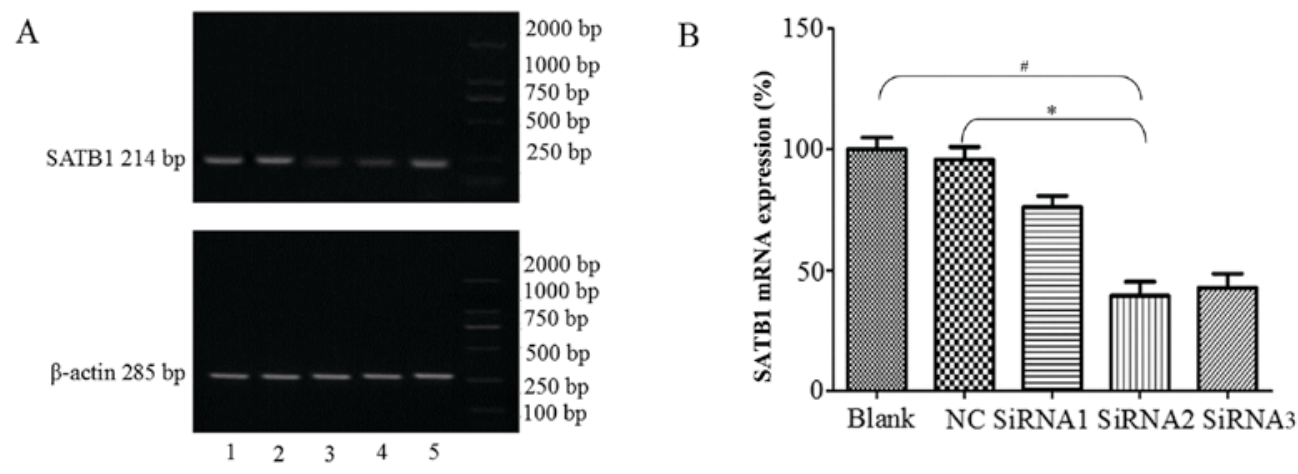

1,SiRNA3;2,SiRNA2;3,SiRNA1;4,NC;5,Blank

Figure 2. Reverse transcription-quantitative polymerase chain reaction analysis of SATB1 mRNA expression following siRNA transfection. (A) Levels of SATB1 mRNA expression following 48-h transfection. The amplified fragment was of the expected size. (B) The results were quantified and significantly lower levels of SATB1 mRNA expression were observed following siRNA2 transfection compared with the NC and Blank groups. "P<0.05 vs. the NC group and ${ }^{\#} \mathrm{P}<0.05$ vs. the blank group $(\mathrm{n}=5)$. SATB1, special AT-rich sequence-binding protein 1; NC, negative control; siRNA, short interfering RNA.
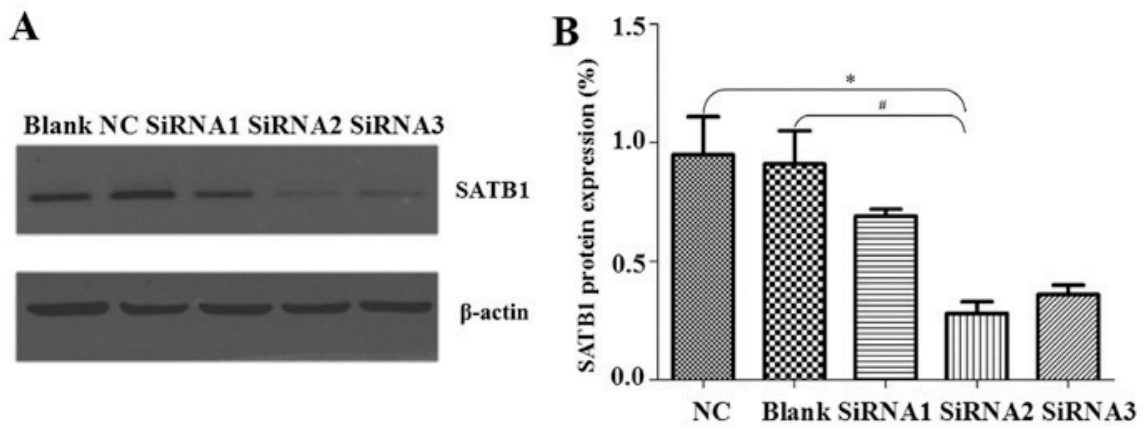

Figure 3. Protein expression levels of SATB1. (A) Western blot analysis was performed to determine SATB1 protein expression levels following siRNA2 transfection compared with the NC and Blank groups $(\mathrm{n}=5)$. (B) ImageJ quantitation of the band densities from the western blot analysis of SATB1 was performed. "P $<0.05$ vs. the $\mathrm{NC}$ group and ${ }^{\#} \mathrm{P}<0.05$ vs. the blank group. SATB1, special AT-rich sequence-binding protein 1; NC, negative control; siRNA, short interfering RNA.

The levels of MMP2 protein expression were also determined by western blot analysis. MMP2 is involved in radical decomposition of the basement membrane and its overexpression is closely associated with the metastasis of malignant tumors (17). MMP2 protein levels were significantly reduced by siRNA2 transfection compared with the levels in the $\mathrm{NC}$ and Blank groups $(\mathrm{P}<0.05$; Fig. 4A and B). MMP2 expression was $0.50 \pm 0.06 \%$ in the siRNA2 transfection group, $1.04 \pm 0.05 \%$ in the $\mathrm{NC}$ group and $0.89 \pm 0.10 \%$ in the Blank group.

Silencing SATB1 inhibits the growth of DU145 and NHLF cells. siRNA2 was transfected into DU145 and NHLF cells and their viability was investigated using a CCK- 8 assay. CCK- 8 demonstrated that siRNA2 significantly inhibited DU145 cell viability compared with the level in the $\mathrm{NC}$ and Blank groups $(\mathrm{P}<0.05)$. The DU145 cell viability rate following siRNA2 transfection was $81.65 \pm 1.91 \%, 58.07 \pm 2.53 \%$ and $53.16 \pm 2.31 \%$ at 24,48 and $72 \mathrm{~h}$, respectively, following transfection (Fig. 5A). In the NHLF cells siRNA2 transfection had similar toxic effects compared with the $\mathrm{NC}$ and Blank groups, no significant differences were observed (Fig. 5B).

SiRNA2 reduces cell adhesion, migration and invasive capability in DU145 cells. DU145 cell adhesion capability was evaluated using a cell adhesion assay, the migration capability was evaluated using a Transwell migration assay and the invasive capability was evaluated using a Transwell invasion assay. The adhesion assay demonstrated that siRNA2 significantly inhibited adhesion between DU145 cells and the cell-extracellular matrix compared with that observed in the Blank and $\mathrm{NC}$ groups $(\mathrm{P}<0.05)$; the cell adhesion capability was $18 \pm 6 \%$ in the siRNA2 transfection group, $34 \pm 4 \%$ in the NC group and $37 \pm 6 \%$ in the Blank group (Fig. 6A). At $24 \mathrm{~h}$, the number of migrated cells in the siRNA2 transfection group, $\mathrm{NC}$ group and Blank group was $49.08 \pm 10.64,115.47 \pm 5.98$ and $122.53 \pm 6.06$, respectively (Fig. 6B). The siRNA2 transfection group had a significantly reduced number of migrated cells compared with the number in the NC and Blanks groups $(\mathrm{P}<0.05)$. DU145 cell invasive ability was significantly inhibited $48 \mathrm{~h}$ following siRNA2 transfection compared with the number in the NC and Blanks groups $(\mathrm{P}<0.05)$. The number of invading cells was $136.60 \pm 10.31$ in the siRNA2 transfection group, $270.19 \pm 11.70$ in the NC group and 276.56 \pm 17.95 in the Blank group (Fig. 6C).

\section{Discussion}

Prostate cancer is the most frequently diagnosed non-skin cancer among men and presents a global public health problem (18). At present, there is limited information available to determine which cases of prostate cancer are likely to 

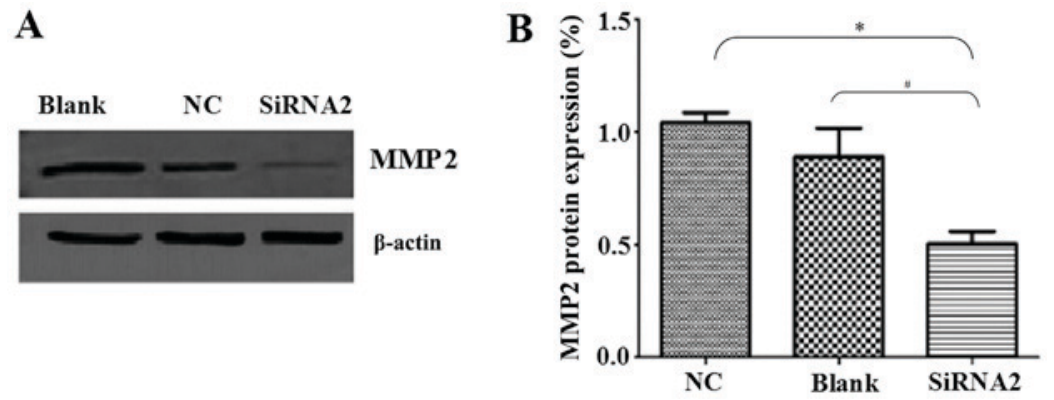

Figure 4. Protein expression levels of MMP2. (A) Western blot analysis was performed to determine the MMP2 protein expression following siRNA2 transfection compared with the NC and Blank groups $(\mathrm{n}=5)$. (B) ImageJ quantitation of the band densities from the western blot analysis of MMP2 was performed. ${ }^{*} \mathrm{P}<0.05$ vs. the NC group and ${ }^{\#} \mathrm{P}<0.05$ vs. the blank group. MMP2, matrix metalloproteinase 2; NC, negative control; siRNA, short interfering RNA.
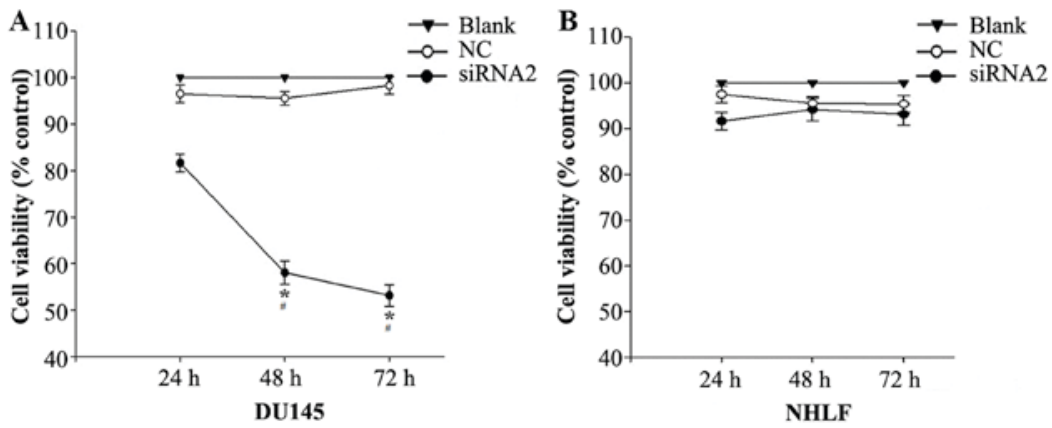

Figure 5. Comparison of cell viability rates. A Cell Counting kit-8 assay demonstrated that siRNA2 significantly inhibited (A) DU145 cell viability compared with the NC and Blank groups at 48 and $72 \mathrm{~h}(\mathrm{n}=5)$. (B) In the NHLF cells siRNA2 transfection had similar toxic effects compared with the level in the NC and Blank groups at 48 and $72 \mathrm{~h}(\mathrm{n}=5)$. " $\mathrm{P}<0.05$ vs. the NC group and ${ }^{\#} \mathrm{P}<0.05$ vs. the blank group. NHLF, normal human lung fibroblast; NC, negative control; siRNA, short interfering RNA.
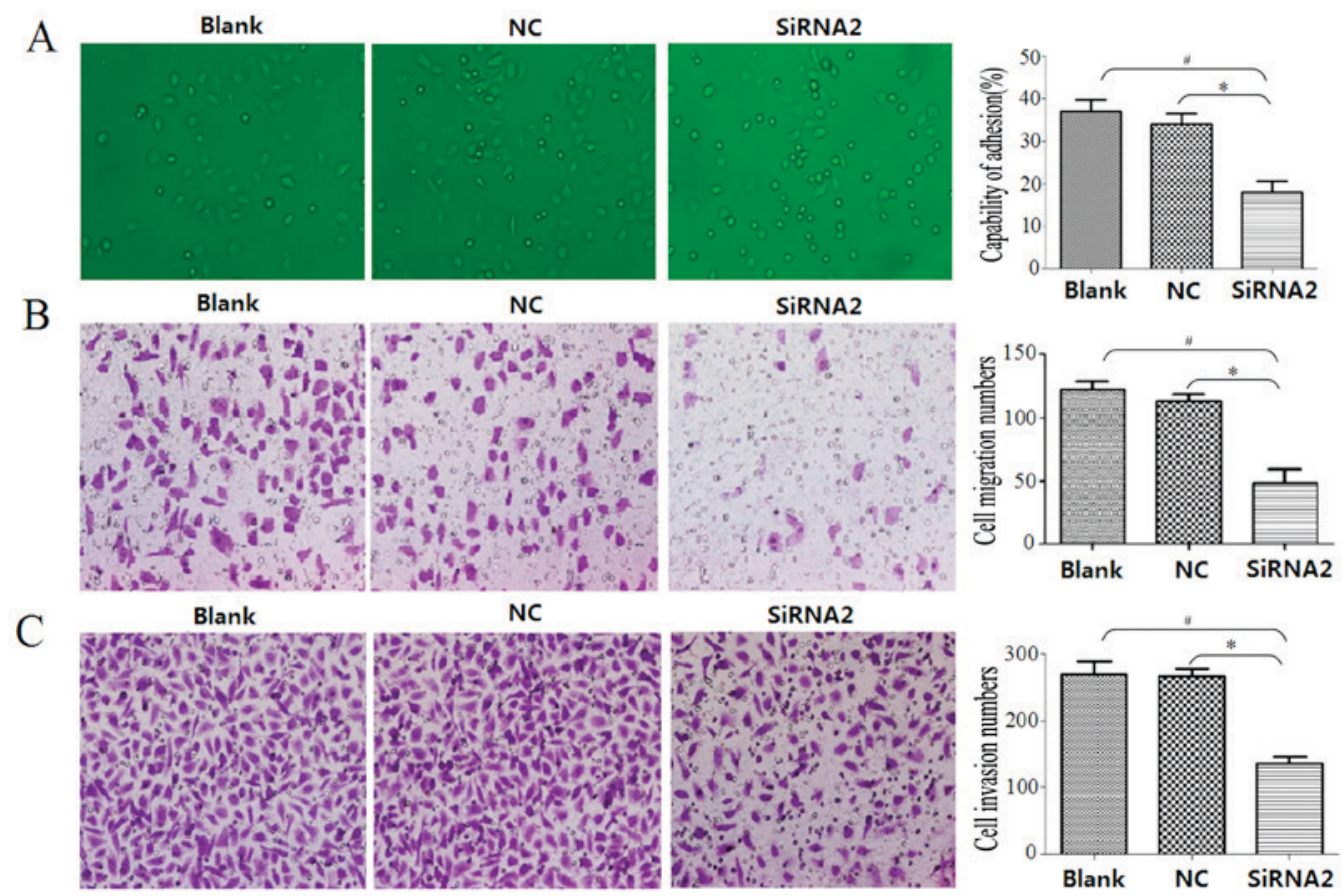

Figure 6. DU145 cell migration, invasion and adhesion. (A) An adhesion assay demonstrated that siRNA2 significantly inhibited DU145-extra cellular matrix adhesion $(\mathrm{n}=5)$. siRNA transfection also significantly inhibited (B) cell migration at $24 \mathrm{~h}$ following transfection and (C) cell invasive ability $48 \mathrm{~h}$ following transfection ( $\mathrm{n}=5$ ). ${ }^{*} \mathrm{P}<0.05$ vs. the NC group and ${ }^{~} \mathrm{P}<0.05$ vs. the blank group (magnification, $\mathrm{x} 200$ ). NC, negative control; siRNA, short interfering RNA.

remain latent vs. those that are likely to metastasize and require additional aggressive treatment (19). SATB1 has been proposed as a potential oncogene, and siRNA-mediated knockdown of SATB1 in aggressive cancer cells has been demonstrated to 
inhibit tumor growth and metastasis (20). Previous studies have suggested that SATB1 modulates cell proliferation and lineage development and it has been implicated in breast cancer (21).

In the present study, it was demonstrated that SATB1 siRNA effectively inhibited the viability of prostate DU145 cancer cells. The levels of SATB1 mRNA expression following transfection with SATB1 siRNA2 were significantly lower than that in the NC group. siRNA2 was transfected into DU145 and NHLF cells and a CCK-8 assay revealed that siRNA2 significantly inhibited DU145 cell viability compared with the NC and Blank groups. siRNA2 transfection had similar effects in the NHLF cells.

Western blot analysis revealed that the levels of SATB1 and MMP2 protein expression following siRNA2 transfection were significantly lower than the NC group. The adhesion assay demonstrated that siRNA2 significantly inhibited the adhesion between DU145 cells and the cell-extracellular matrix.

In a previous study, it was observed that SATB1 staining was stronger in prostatic carcinoma with metastasis than in prostatic carcinoma without metastasis and was absent in benign prostate hyperplasia (11). These results suggest that SATB1 is crucially implicated in the metastasis of prostate cancer (11). In the present study, SATB1 siRNA inhibited prostate cancer cell invasion effectively in vitro. These results are consistent with a previous study that reported that pSilencer-SATB1-short hairpin (sh)RNA was markedly efficacious against prostate cancer xenografts in nude mice (20).

Mao et al (22) reported that the toxicity of the oncolytic adenovirus (OAds) carrying shRNA targeting SATB1 was reduced by generating E1B 55-kDa-deleted OAds. However, others have reported that the oncolytic anti-tumor activity of OAds, including reducing the circulation time, inducing immunogenicity and increasing the accumulation and toxicity in the liver, are insufficient for effectively eliminating tumors (23). Therefore, there is an urgent requirement for the development of novel treatments.

In the present study, it was demonstrated that silencing SATB1 significantly inhibited DU145 cell viability, adhesion, migration and invasion in vitro, indicating that a SATB1-targeting siRNA was successfully engineered. The approach exhibited clear anti-cancer cell efficacy. The results of the present study suggest that SATB1 siRNA may be a promising agent for the treatment of human prostate cancer, although further studies are required in vivo to confirm this.

\section{References}

1. Suh YS, Joung JY, Kim SH, Seo HK, Chung J and Lee KH: Establishment and application of prostate cancer circulating tumor cells in the Era of precision medicine. Biomed Res Int 2017: 7206307, 2017.

2. Yamoah K, Beecham K, Hegarty SE, Hyslop T, Showalter T and Yarney J: Early results of prostate cancer radiation therapy: An analysis with emphasis on research strategies to improve treatment delivery and outcomes. BMC Cancer 13: 23, 2013.

3. Pinkawa M, Schoth F, Böhmer D, Hatiboglu G, Sharabi A, Song D and Eble MJ: Current standards and future directions for prostate cancer radiation therapy. Expert Rev Anticancer Ther 13: 75-88, 2013.
4. Barret E, Harvey-Bryan KA, Sanchez-Salas R, Rozet F, Galiano M and Cathelineau X: How to diagnose and treat focal therapy failure and recurrence? Curr Opin Urol 24: 241-246, 2014.

5. Qin J, Lee HJ, Wu SP, Lin SC, Lanz RB, Creighton CJ, DeMayo FJ, Tsai SY and Tsai MJ: Androgen deprivation-induced $\mathrm{NCoA} 2$ promotes metastatic and castration-resistant prostate cancer. J Clin Invest 124: 5013-5026, 2014.

6. Tattermusch A and Brockdorff N: A scaffold for X chromosome inactivation. Hum Genet 130: 247-253, 2011.

7. Ye CS, Zhou DN, Yang QQ and Deng YF: Silencing SATB1 influences cell invasion, migration, proliferation, and drug resistance in nasopharyngeal carcinoma. Int J Clin Exp Pathol 7: 914-922, 2014

8. Zhang L, Cheng F, He R, Chen H, Liu Y and Sun J: Inhibition of SATB1 by shRNA suppresses the proliferation of cutaneous malignant melanoma. Cancer Biother Radiopharm 29: 77-82, 2014.

9. Zhang H, Su X, Guo L, Zhong L, Li W, Yue Z, Wang X, Mu Y, Li X, Li R and Wang Z: Silencing SATB1 inhibits the malignant phenotype and increases sensitivity of human osteosarcoma U2OS cells to arsenic trioxide. Int J Med Sci 11: 1262-1269, 2014.

10. Huang B, Zhou H, Wang X and Liu Z: Silencing SATB1 with siRNA inhibits the proliferation and invasion of small cell lung cancer cells. Cancer Cell Int 13: 8,2013.

11. Mao L, Yang C, Wang J, Li W, Wen R, Chen J and Zheng J: SATB1 is overexpressed in metastatic prostate cancer and promotes prostate cancer cell growth and invasion. J Transl Med 11: 111, 2013

12. Betáková T and Svančarová P: Role and application of RNA interference in replication of influenza viruses. Acta Virol 57: 97-104, 2013.

13. Song Y, Liu C, Liu X, Trottier J, Beaudoin M, Zhang L, Pope C, Peng G, Barbier O, Zhong X, et al: H19 promotes cholestatic liver fibrosis by preventing ZEB1-mediated inhibition of epithelial cell adhesion molecule. Hepatology 66: 1183-1196, 2017.

14. Li X, Chen H, Xue L, Pang X, Zhang X, Zhu Z, Zhu W, Wang Z and $\mathrm{Wu} \mathrm{H}$ : p53 performs an essential role in mediating the oncogenic stimulus triggered by loss of expression of neurofibromatosis type 2 during in vitro tumor progression. Oncol Lett 14: 2223-2231, 2017.

15. Zhao L, Gu J, Dong A, Zhang Y, Zhong L, He L, Wang Y, Zhang J, Zhang Z, Huiwang J, et al: Potent antitumour activity of oncolytic adenovirus expressing mda-7/IL-24 for colorectal cancer. Hum Gene Ther 16: 845-858, 2005.

16. Zheng Y, Liu W, Guo L and Yang X: The expression level of miR-203 in patients with gastric cancer and its clinical significance. Pathol Res Pract 213: 1515-1518, 2017.

17. Roomi MW, Kalinovsky T, Rath M and Niedzwiecki A: A nutrient mixture inhibits glioblastoma xenograft U-87 MG growth in male nude mice. Exp Oncol 38: 54-56, 2016.

18. Chen CB, Eurich DT, Majumdar SR and Johnson JA: Risk of prostate cancer across different racial/ethnic groups in men with diabetes: A retrospective cohort study. Diabet Med 35: 107-111, 2018.

19. Tu W, Luo M, Wang Z, Yan W, Xia Y, Deng H, He J, Han P and Tian D: Upregulation of SATB1 promotes tumor growth and metastasis in liver cancer. Liver Int 32: 1064-1078, 2012.

20. Wang Q, Hu SC, Yang CS, Chen JC, Zheng JN, Sun XQ and Wang JQ: Inhibition of prostate cancer cell growth in vivo with short hairpin RNA targeting SATB1. Oncol Lett 14: 6592-6596, 2017.

21. Han HJ, Russo J, Kohwi Y and Kohwi-Shigematsu T: SATB1 reprogrammes gene expression to promote breast tumor growth and metastasis. Nature 452: 187-193, 2008.

22. Mao LJ, Zhang J, Liu N, Fan L, Yang DR, Xue BX, Shan YX and Zheng JN: Oncolytic virus carrying shRNA targeting SATB1 inhibits prostate cancer growth and metastasis. Tumour Biol 36: 9073-9081, 2015

23. Choi JW, Lee JS, Kim SW and Yun CO: Evolution of oncolytic adenovirus for cancer treatment. Adv Drug Deliv Rev 64: 720-729, 2012. 